\title{
The Study on the Transformation of Disney Animated films Based on Consumerism
}

\author{
Yang Xiao ${ }^{1, a, \dagger, *}$, Ziqi Xiao ${ }^{2, b, \dagger, *}$, Zhuyanyan Xue $\mathrm{X}^{3, \mathrm{c}, \uparrow, *}$ \\ ${ }^{1}$ School of Communication, Hong Kong Baptist University \\ ${ }^{2}$ School of Journalism and Communication Guangzhou University \\ ${ }^{3}$ Pennsylvania State University \\ *Corresponding author.Email: a $18252869 @$ life.hkbu.edu.hk, ${ }^{b} 1820300066 @ e . g z h u . e d u . c n,{ }^{c} z k x 5045 @ p s u . e d u$ \\ ${ }^{\dagger}$ These authors contributed equally.
}

\begin{abstract}
Disney animated films have always been about the exploration of humanity and heroes. However, there is only one purpose of its exploration: to meet the current consumer market. To achieve this goal, Disney has constantly been changing. When postmodernism dominates, consumers have changed, and Disney animated films have also changed in both content and form in response to changes in the situation. This paper will take consumerism as the main research perspective to sort out the transformation of Disney animated films and further explore the current changes of Disney animated films from the content and form.
\end{abstract}

Keywords: Disney, animated film, consumerism

\section{INTRODUCTION}

"We can't deny the fact that most people live in the established ideas. They are attached to the established ideas and regard them as the blueprint of all activities", Featherstone said. [1] However, in the post-modern era, the so-called established views are also developing and changing. That is, they should be viewed from the perspective of diversity. In the post-modern society, all kinds of consumer goods, companies, and industries are transforming consumerism. In this case, the role of consumers has been redefined, and they have become a more important factor than consumer goods. In the film industry, a very typical case is the transformation of Disney. From the "Snow White and the Seven Dwarfs" in 1937 to the recent movies like "Frozen" ,Coco," and "Soul", Disney has undergone several transformations, especially in Post Walt Disney Era. By exploring this continuous transformation, we can find a clear clue that both the changes in content and the changes in market and technology are closely related to consumerism.

\section{THE TRANSFORMATIONS FROM A HISTORICAL PERSPECTIVE}

To explore these transformations, we need to start from Disney's earlier period. The first trial of Disney animated films can be traced back to the 1930s.In 1937,"Snow White and the Seven Dwarfs", marked Disney's entry into the era of full-length animated film creation. Since then, Disney's creation has matured gradually and ushered in a golden age in 1950. The animated films had obvious fantasy colors and deliberately created some distinctive and romantic heroic images. It is this magic charm that attracts a large number of audiences. Since Walt Disney passed away in 1966, Disney entered the bottleneck of inspiration exhaustion. We will start from this period to discuss the transformation process of Disney animated films.

\subsection{Exploration period (1967-1988)}

In the middle and late $1960 \mathrm{~s}$, frequent international wars, domestic political scandals, and various civil rights movements constantly impacted people's thoughts and values. Therefore, American films focused more on the confused and angry social youth and created many different "anti-hero" images. In the late 1970s, with the rise of conservatism and the aggravation of economic depression, people hoped to seek hope in movies."The traitors, losers, and loners who used to be full of American movies have disappeared, and given way to ordinary citizens searching for meaning in the ordinary society... As a result, good people become good people again, while bad people are still the bad people. Heroes, 
replace anti-heroes, and reunion replaces tragic ending. The rebellious spirit of the new American film era has disappeared." [2] Based on this background, we can analyze the transformation of Disney from the content and form.

\subsubsection{Film content}

In the 1970 s, to meet the audience's needs, Disney began to deliberately shape a "different" hero image that is different from the previous aesthetic orientation. In "The Aristocasts" and "Robin Hood", heroes became a cat and a fox, which are not perfect but doing justice.

Since the late 1970s, the perfect image of classical heroes has changed from highlighting the hero's personal strength to emphasizing the hero's wisdom. Moreover, the early individualism and the later unity and cooperation also form a sharp contrast. More importantly, the hero's glory no longer belongs to the protagonist. It also gives those ordinary characters in the animation.

\subsubsection{Film form}

For Hollywood owners, the huge success of the film "Jaws" in 1975 and "Star War" in 1977 taught them to use high technology to please the young audience and pursue the huge box office revenue.

Under this tone, Disney applied computer technology initially. Disney also made animated films a spectacle "blockbuster". In 1988,"Who Framed Roger Rabbit" became an important starting point of this change. Since then, no animated film is not high cost, high production, great momentum, and big publicity. The only purpose of all the changes is to better present the role and meet the audience's needs.

\subsection{Prosperous period (1989-2000)}

This period spanned the whole 1990s and created several Disney animated films with world influence. Like American movies, Disney animated movies no longer cater to local audiences but want a larger world market.

\subsubsection{Film content}

Disney animation has become more and more diversified in story selection, and it has also reached an unprecedented peak in shaping hero images. It included "Aladdin" and "Hercules", mythological adaptations from the Middle East, "Pocahontas" and "Mulan" from the historical legends, "Tarzan" and "The Hunchback of Notre Dame" from famous literary works, even "The Lion King", the first original work.

Disney fully explored the cultures from the world while reconstructed them with American values. The establishment of hero identity no longer depends on the background setting but the character's independent choice. In the process of completing the heroic mission, they will have confusion and real emotions. Through the description of the inner changes of the characters, the audience can truly enter the hearts of the characters.

\subsubsection{Film form}

In this period, Disney has developed from simple hand-painted animation to multiform animation." Toy Story", three-dimensional made entirely on a computer in 1995, ushered in a new era of American animated films. Furthermore, Disney also tried to open a new direction by making films with clay models. Both" The Nightmare Before Christmas" and "James and the Giant Peach" all made great success.

Since the 1990s, once an animated film got successful, it will be transformed into various forms, such as musicals, ice shows, TV series, and film sequels. Disney took advantage of the commercial value of animated films and transformed them into various forms to obtain benefits, which also reached unprecedented maturity.

\subsection{Transition period (since 2001)}

Since entering the new century, Audiences began to complain that Disney's films were becoming more and more old-fashioned, while Disney's competitors actively craved up the market."No matter from the domestic animation field or the world animation field, we can see that the past era of Disneyland covering the sky with one hand is gone, and the worldwide disputes replace it." [3] A series of box office fiascos made the transformation imperative. We can still make a brief analyze it from the following aspects.

\subsubsection{Film content}

In the early decades, Disney animated films have been streaming in three directions: great heroism and surrealism, like"Treasure Planet"," Wreck-It Ralph"," Big Hero 6", the return of human warmth under the cold diaphragm of modern society, like "Meet the Robinsons", "Bolt" and "Zootopia", modern fables in fairy tales' coat, like "Tangled"," Brave" and "Frozen".

During this period, Disney animated films began to show the multi themes and discourses. They contain the highlight and worship of science and technology, emphasizing personal discourse and individual care, and even the irony and joking of the real world. Everywhere is the demonstration of American values. The identities of heroes became more diverse, and mortal heroes, romantic heroes, and even contrast heroes frequently appear in the animation. At the same time, Disney no longer deliberately depicts the growth process of the hero but only inserts the transformation of the hero into the turning point of the plot. Their action mode is from "egoism" to "sacrifice oneself for others", and the 
establishment of hero identity depends on the establishment of great achievements and knowing oneself, pursuing oneself, and even breaking through oneself.

\subsubsection{Film form}

In the face of competitors, Disney launched a series of acquisitions from PIXAR to 21ST CENTURY FOX, making animated films more diversified.

Compared with the failure of traditional hand-painted animated film, CG technology has gradually become the world trend. Therefore, Disney gave the traditional handpainted up totally and began to develop new technology. Nowadays, both CG and 3D animation have become the main production support of Disney. The development of new technology has led to a series of the new creation of narrative, characters, and pictures.

It is understandable for Disney to embark on such a road from the perspective of commercial interests. However, for many people in the animation industry, the decision made by Disney animation is heartbreaking.

In recent years, the animated films about great heroism and surrealism were gradually decreasing. In contrast, the more experiential films and paid more attention to public opinion are just the opposite. The reasons behind this deserve to be analyzed deeply below.

\section{THE REVOLUTION OF DISNEY'S CHARACTER LIBRARY}

Over the past decades, Disney's character libraries have to keep exploring how to touch the public's hearts no matter in history or at present, whose path is twisty and complicated. Aimed at catering to the changes in the consumer market, Disney is keeping the revolution based on the theory of post humanism. Transhumanism is an embranchment of the post humanism theory. This cultural movement affirms the use of techniques to increase the likelihood that human beings can transcend the boundaries of their current existence [4]. In today's retrospective, we could see that superheroes' characters originated from transhumanism, as they were endowed with non-human power.

In recent years, another new thought is silently streaming and quickly occupy the film market. The information Disney' $\mathrm{s}$ film willing to convey has transformed from the external power of ability into internal psychic feeling. Originally, people perceive films as their dream makers because they hope to have a wonderful and successful life as the leading characters in the films. With more attention paid to themselves, people nowadays are not afraid to face the dark side of the personality. Moreover, they are willing to discuss the topic of fear, disappointment, and ordinary, which are not acceptable in the previous mainstream ideology. In the following part, we will see how Disney' s cartoon film Frozen, Coco, and Soul transform its content and spirit under the post modernism and consumerism.

Fear is a kind of intense repressed emotional experience that people have when faced with a certain dangerous situation, which is quite common in people's daily attitudes. Unlike traditional movies, with deeply describing the issues of fear, Frozen is the first obvious movie that highlights the real human with portraying their complicated emotions. Apart from its fantastic animation effects, one of the most important criteria that contributed to its wonderful achievement is that this movie has raised people's thoughts about humanity's dark side. Through the film, the audience can see how Elsa successfully protects her sister and her fear, anger, anxiety, and other negative attitudes, through which the audience can still derive value from the reverse. This movie breaks with the stereotype that Disney's animations rarely show "human complexity", appearing with the depth of human emotion, and reflecting a sense of morality that values human relationships. This is a typical application with postmodern culture, as it corresponds to a daily attitude. Different from only agree with one attitude, people's values begin to diverge and would like to show their diversity from complicated products or characters. Disney caught this point and started to fulfill people's needs by creating characters with complicated human emotions, making this first obvious transaction a success. However, we could still see the shadow of a superhero in Frozen. Considering the extraordinary power of creating ice and snow, the superhero genre is still useful for approaching Elsa's portrayal [5]. Indeed, as presented in the parody, instead of following the stereotyped superheroes, the creation of Elsa appears a new stream and but with issues of fear, power, and control.

Heroes never die in the film, and storytellers always avoid discussing such heavy topics in the film for public discussion. Some people may even reject it, as it goes against the traditional mainstream value of enjoying the positive aspects of life. However, after four years of Frozen, Disney had another successful animation movie concentrating on death in a pleasant, relax, and light mood. Inspired by the Day of the Dead in Mexico, the film Coco tells the story of Miguel, a music-loving boy, and Hector, an underdog musician, who embark on a fantastic adventure in a mysterious world of colorful scenes. Priority, this movie aimed at educating people on how to chase their dream. However, the audience can perceive a deeper understanding of death in the wellrounded story. With fully dimensional characters, grisly brushstrokes that are both gentle and humorous, and vivid and beautiful visuals, the audience easily accept thinking of death. Such a heavy topic narrating in playful storytelling is an obvious appearance of consumerism and postmodern culture, as it goes against the traditional serious tone. Generally speaking, if the film talks about 
death, it may be hurtful, painful, and solemn. However, the postmodern culture agrees that people should follow their desire, instinct, and enjoyment, which means that people are willing to pay the tickets if the film is playful and relaxed. Additionally, both the light narrating tone itself and the complexity and contradiction of human nature are the appearance of the diversity in postmodern culture. They reflect the different values that people could easily accept.

Superheroes always avoid the ordinary, but we cannot deny that most of us are not destined for excellent achievement. Disney caught the moment when people are in obscurity and emerged the topic of how to bear a long time for working hard and waiting for chances as a new film, Soul. Released last year, Soul is a milestone in the character transaction, persuading the audience to accept and enjoy every moment during our life journey. In this film, some typical lines praise the sun, the wind, and everything in daily life, which is the appearance of anesthetization of everyday life from consumerism and postmodern culture. If we examine various definitions of postmodernism, it is not difficult to find that one of the key points of these definitions is that the boundary between art and daily life, between high art and popular culture, has been broken down. Instead, a variety of hodgepodge-type word games and symbolic games have been overrun. This is the result of the anesthetization of everyday life. Instead of remembering the rush hour or the highlight time, Soul stimulates that our everyday life weighs more importance.

Overall, in the post-modernism society, people welcome diversified values, lifestyles, personalities, and more acceptable to a broad definition of humanistic. They are willing to hear different voices and see more 'darkside' topics appearing on the screen, which can be proved through the great achievements the above three movies have gained. Which topic will be the next after fear, death, and ordinary? We are waiting to see more transactions in Disney's characters and films.

\section{MARKETING STRATEGY}

Just as previously mentioned, the Disney films about heroes followed current society's consumption concept and consequently brought tremendous marketing success and professional, positive feedbacks. All of the three films have won many important awards, including Golden Globe Award and Academy Award. Moreover, the box office attainments of the three films were very high that Frozen even earned over $\$ 1.3$ billion box office. Certainly, the films' success not only owes the content change but also on marketing strategy and promoting technology. The patterns of consumption are changing throughout the various product or service portfolios bearing the behaviors of consumers. The needs of consumers change because their experiences are also changing. From the beginning, Disney insisted on combining content and form, market and films together to follow consumerism, so it could always achieve big success.

Instead, factors such as value and status are taking precedence in the purchase trends. That is a pattern that Disney Co. has noted, considering the elements of such changes in their contemporary marketing strategy. Like other market leaders, Disney has considered the inputs of Mike Featherstone in his work Consumer Culture and Postmodernism 2nd ed [1]. I explore Disney's marketing strategies through its breakthrough films: Frozen, Soul, and Coco, by referring to Featherstone's inputs on consumer culture changes. The analysis unearths Disney's marketing aspects as it creates an understanding of data collection on consumer mental changes and the changes in marketing strategies.

Frozen is one of the films that employed Featherstone's emotional theory to steer its sales. The emergence of the internet in marketing implies a wider understanding of what consumers need. The unique aspect of Frozen's marketing was that it swayed emotions through markets that were segmented into videos, games, and animations that attracted different audience categories [6]. The character of Elsa, for instance, moved from traditional heroism to a more reflective and humanlike character. Disney understands the emotions that people attach to these films. The audience wants to relate as much as possible to the characters. Segmenting such emotions to explore different platforms for the film further swayed more people who were not even attracted to the film aspects but the human aspects in Frozen.

Frozen is also a testament to morality in film by showing the depth of human emotions and their impacts on contemporary marketing. Disney films traditionally revolved around complex characters that barely showed any emotional weaknesses. It was superficial in cases where emotions were shown, and viewers could relate to the un-human-like characters. Frozen defies the tradition by delving into the depths of human emotions. Through this Elsa, one is treated to a hero who bears human characteristics. This hero sets achievable moral standards. People are beginning to diversify their emotions to accommodate the prospects of their real lives. Films that are unilateral and mostly superficial in expressing such emotions are largely becoming unreal or un-relatable. Emotional selling has developed into a vital marketing strategy. Organizations such as Disney have noted that emotions influence what people consume or purchase decisions. When people associate positive or negative feelings with something, they are likely to decide to sell or ignore them. Elsa is a representation of positive emotional feelings. Her character makes people more attached to the film. Viewers would watch Elsa simply because she triggers positive feelings on how people deal with challenges such as rescuing family and friends. 
The economic and social theory mark their imprints in Soul and Coco. Their perceptions and attraction mark changes in consumer social positioning to various films. In Soul, Pixar production was a unique marketing position that should motivate people to enjoy the social moments. The characters are framed to mirror the contemporary social context. Using Pixar, the producers interacted with the viewer's social needs [7]. Pixar allowed the producers to focus only on factors that enticed the majority. Such a robust marketing strategy matches Featherstone's [1] inputs that marketers must understand the tenets of the three theories behind cultural change. Social interactions have grown valuable in how people perceive their environments. Even more notable is relating the social needs of consumers with the services.

Coco explored the economic aspect of consumer culture to deliver Disney into yet another successful film. The film explores the economic challenges of the present day, with people exploring different paths to fit in the ideal economic realm. Amidst the growth, individuals learn the challenges of success and even contemplate the ills such as stealing. Coco diverts from the traditional premise of pursuing dreams to show the challenges individuals must surpass to meet such dreams. Moreover, the fast development speed of the current society brings unprecedented mental pressure to residents. Sense of loss frequently appeared in people's minds in this competitive world, so Coco pays more attention to the poor eld to bring out resonance. By instilling reality in entertainment, Disney proved that they are more concerned about relating individual experiences with character behaviors in their films.

The use of different media platforms to reach the target audience was notable in Disney's move to market its films. The value of multimedia marketing has grossed due to diverse perceptions that consumers have developed across different media outlets. Additionally, consumers are also spoilt for choice in media use, something that steers marketers to explore every available platform to interact with their consumers. Featherstone [1] notes the value of multimedia marketing by insisting that signs can float free from objects and are available for use in an assortment of associative relations. Hence, the more a brand triggers associative relations, the better the reception such a brand can command from varying consumer groups.

The three Disney films above employed an assortment of media that worked to their advantage. The internet is easing interactions between content creators and consumers. Each day, sellers understand the needs of their viewers on a global scale. Creating content that matches the most needs is made simple through the internet. Each Frozen, Soul, and Coco was accorded a unique internet portfolio to access different customer groups. Upon their success in using social media for Coco, Disney resorted to an even more robust use of multimedia to deliver its targets [7]. For instance, Frozen was treated to a specific YouTube channel to air its trailers. Through such a strategy, consumers had unlimited access to the content without associating it with the company's image. The film was also linked to other social media timelines on Twitter, Facebook, and Instagram, giving it an even bigger appeal as an independent franchise. Still, outlets such as radio, television, and billboards played a role in marketing the films. In the end, diversity in media use coincided with segmented markets to deliver success for the films. Segmenting markets through different media platforms creates product/service appeal to people on different levels. The internet has created a variety of marketing platforms. They were staying traditional, and marketing in specific avenues such as the mainstream media only limits consumption. Disney employed a versatile marketing strategy in the three films to ensure that every potential viewer gave them a chance.

Marketing is advancing to match the emerging consumer needs. Notably, consumers expect to satisfy their expectations and even those they only perceive in dreams. In the case of Disney, efforts have been put to instill a better use of the changes in consumer culture for better outcomes. To Disney, the new changes have steered them into collecting more information from customers to address their needs. Also, they can target different market segments with unique multimedia marketing strategies. Such versatility steered them to success in Frozen, Soul, and Coco.

\section{CONCLUSION}

Whether in the past or nowadays, Disney films connect their content with their format and marketing strategies to achieve success. Disney completed a breakthrough in this time's change-- the highlight point of main characters transferred from physical to mental, from positive to negative. In postmodern society, the biggest consistency of Disney Co. is keeping changing. I believe Disney will insist on this trend and change for consumers in the future.

\section{REFERENCES}

[1] Featherstone, M, Emerson, Consumer Culture and Postmodeernism. Publisher: Sage publications Ltd; Second Edition, 2007: 172

[2] Sun Lijun, Ma Hua, M, Explore the Art of the Disney's Animation. Publisher: Jinghua publication Ltd;2010:107

[3] Sun Lijun, Ma Hua, M, Explore the Art of the Disney's Animation. Publisher: Jinghua publication Ltd;2010:257 
[4] Rosendahl Thomsen, Mads, \& Wamberg, Jacob. (2020). The Bloomsbury Handbook of Posthumanism. Bloomsbury Publishing Plc.

[5] Benhamou, Eve. (2014). Freezing versus wrecking: Reworking the superhero genre in Disney' $\mathrm{s}$ Frozen (2013) and Wreck-It Ralph (2012). Animation Practice, Process \& Production, 4(1), 13 - 26. https://doi.org/10.1386/ap3.4.1.13_1

[6] Thomas, S. Disney Marketing Strategy: How Disney Dominates the Entertainment Industry. 2021, Retrieved from https://avada.io/resources/disneymarketing-strategy.html

[7] Petersen, P. The Business Model of the Walt Disney Company: Evaluating the potential of the business model in terms of its competitiveness. 2018, Munich: München GRIN Verlag. 